http://www.jfas.info

\title{
THE RELATIONSHIP BETWEEN INTERNAL AND EXTERNAL LOCUS OF CONTROL OF PARENTS WITH AGGRESSION IN CHILDREN IN PUNITIVE AND NON-PUNITIVE FAMILIES IN MASHHAD
}

\author{
H. Shojaei and E. Zarei \\ University of Hormozgan, Iran
}

Published online: 15 June 2016

\begin{abstract}
This study examined the relationship between internal and external locus of control of parents with aggression in children in punitive and non-punitive families. The method of this study was descriptive and correlational type. The statistic population in this study included parents of children, male and female (age group 12 to 15 years) living in the city of Mashhad that were 24000 families. The 340 families of statistic population were selected as sample by random sampling and using Cochran formula. Research samples were assessed by using questionnaires Rutter locus of control and aggression. The results of the analysis showed that there is relationship between internal locus of control of parents and children aggression in punitive families, and there is relationship between external locus of control of parents and children aggression in punitive families, there is not a relationship between internal locus of control of parents and children aggression in non-punitive families, there is relationship between external locus of control of parents and children aggression in non-punitive families,
\end{abstract}

Author Correspondence, e-mail: authorC@mail.com

doi: http://dx.doi.org/10.4314/jfas.v8i2s.168 
there is relationship between internal locus of control of parents and children aggression in punitive and non-punitive families, there is relationship between external locus of control of parents and children aggression in punitive and non-punitive families, there is a significant difference in aggression between punitive family and non-punitive family, there is a significant difference in external locus of control between punitive family and non-punitive family, and there is a significant difference in internal locus of control between punitive family and non-punitive family.

Keywords: Internal locus of control; external locus of control and aggression.

\section{INTRODUCTION}

When the violent reaction occurs, other family members' behavior will provoke aggressive behavior. For example, when a brother shout at his sister, the sister screams and insults him. Then the brother hit her and the problem continues. All this shows that parents can have a stable behavior for rewarding and punishing their children and by using effective ways without severe punishment, control their children aggression andretraining children in short periods is relatively possible (Shams, 2010).

Children are more vulnerable than other members of society, misbehaving with children includes wide range of harmful behaviors such as not meet basic needs, child abuse, verbal and corporeal punishment, harassment, and emotional and sexual abuse (Ayin, 2005). Corporal punishment involves the use of physical force to cause pain without injury to train (corrected or controlling behavior) in children (Gofin, et al, 2009). In corporeal punishment usually they hit children with hands or an object, such as wood stick, belts, and whips on some parts of the body like hands or buttock or using a hot object to burn children. Corporal punishment is used in many different cultures to control and correct children's behavior (Wolrich et al, 1998). Corporal punishment is forms of child abuse and domestic violence, which violates children's rights and have short-term and long-term adverse effects on children's minds and bodies (Lopez et al, 2000).

Locus of control is a person belief in problem-solving abilities and talents or belief in luck and external factors and as a result having passive environmental conditions. Locus of control 
is how to search information in environment and type of information processing in the events and issues. The concept of locus of control is presented in Rutter Theory. Rutter refers to both external and internal assumptions to express the concept of locus of control. The group is generally refer their successes and failures to themselves (effort or personal ability) are called people with internal locus of control the second group usually refer their successes and failures to outside factors or difficult situations and bad fortunes of the day are called people with external locus of control (Khounejad, 2008).

In Iran, Mohammadi (2011), in study as consequences of corporal punishment achieved the following results: there is a significant relationship between corporal punishment and boys' aggression. There is a direct significant relationship between corporal punishment and girls' depression. There is a significant relationship between corporal punishment and academic failure in both genders.

Malakpour (2010), in a study about the relationship of punishment and self-expression in children and adolescents showed there is a significant relationship between weakness of self-presentation and punishment of a child or adolescent. As it can be seen, this is an inverse relationship, i.e. increasing the punishment on children has reduced the amount of their selfpresentation tactics.

Ghasemi et al. (1386), in a study explores some behavioral problems as a result of corporal punishment by parents of primary school children that housewives and lower educated use corporal punishment and behavioral problems such as verbal and action aggression and, isolation and lack of cooperation in children who were punished by their parents was significantly higher than those who were not punished.

Exploring the relationship between internal and external locus of control parents and their effect on the children's aggression was the cause of researchers attempt to deal with the subject. The answers to all these questions and the findings would be of great help to researchers in this field and by providing the results in papers and magazines can raise the community awareness of the harmful effects children's punishment and take a major step forward in promoting the culture of society.

The main question in this research is that; what is the relationship between internal and 
external locus of control of parental with the children's aggression in punitive and non-punitive families of boys and girls?

\section{METHODOLOGY}

According to the purpose of this study (the relationship between internal and external locus of control of parents with children's aggression of punitive and non-punitive families) the research method is descriptive and correlational.

\subsection{The statistical population, sample and sampling method}

The statistical population of this study included parents and children, male and female (age group 12 to 15 years) living in Mashhad to the number of 24,000 families. The 340 families of statistic population were selected as sample by random sampling and using Cochran formula. The target group in this study is punitive and non-punitive families (parents and children) that are tested by using research tools. The sample size of 378 was calculated by Cochran formula that due to their final loss, research sample of 340 subjects was considered.

\subsection{Instruments}

The collection tools of this study are:

Rutter Control Scale (internally and externally)

This scale is consists of three parts (A, B and C) is. Part A included parents' demographic information (gender, education, age, occupation). Part B contains five questions about punishing children. Part C contains 29 items; each item has a pair of questions (a) and (b). Rutter questionnaire was developed to measure people's expectations in source control, this tool is a pencil - paper questionnaire or objective character of 29 items by Rutter has been prepared to measure the internal and external locus of control. Having high scores on this scale indicate strengthen the belief in external locus of control behavior.

This questionnaire was normalized and standardized by some researchers to run on students. For example, this questionnaire was standardized on students in Mashhad. This questionnaire has been adapted from a research thesis. The original questionnaire was prepared by Rutter in English, and was downloaded from the Internet and also translated some amendments to ensure its validity. As well as to ensure that the questionnaire's reliability, test-retest methods 
were used. In this process, within a week it was conducted twice on a limited number of students (40) who were considered as a complete study population, and Cronbach's alpha showed the number of 0.75 , indicating that the device is reliable.

\subsection{Aggression Questionnaire (AGQ)}

This questionnaire was designed by Zahedifar, Najarian and Shokrkon (1997), in Islamic Azad University of Ahvaz and includes a 30 multiple question that measures by 14 questions are about "anger", 8 items of "aggression" and 8 items of "revenge". Each questionnaire has 4 Likert method options (never, rarely, sometimes or always)and the score is 0, 1, 2 and 3, was considered for them. Score greater than or equal to 45 is considered as aggressive person. This questionnaire was normalized by Zahedifar, Najarian (1996) in Iran and its reliability is reported as 85\% (Najarian, 2007). Also EsmaeiliDehaghi (2006) in a study on about 120 nurses' pediatric hospitals of Medical Sciences of Isfahanachieved about 0.88Cronbach's alpha for questionnaire.

\subsection{Punitive Scale}

In this study, five questions were asked from parents in the second part of the questionnaire that determines what grade parents acquire in punishing their children. Reliability for these 5 questions was 0.789 .

\section{FINDINGS}

Findings of this study were reported in the form of research questions using Pearson correlation coefficients as follows:

Table 1. Pearson's correlation coefficient between locus of control of parents and children's aggression

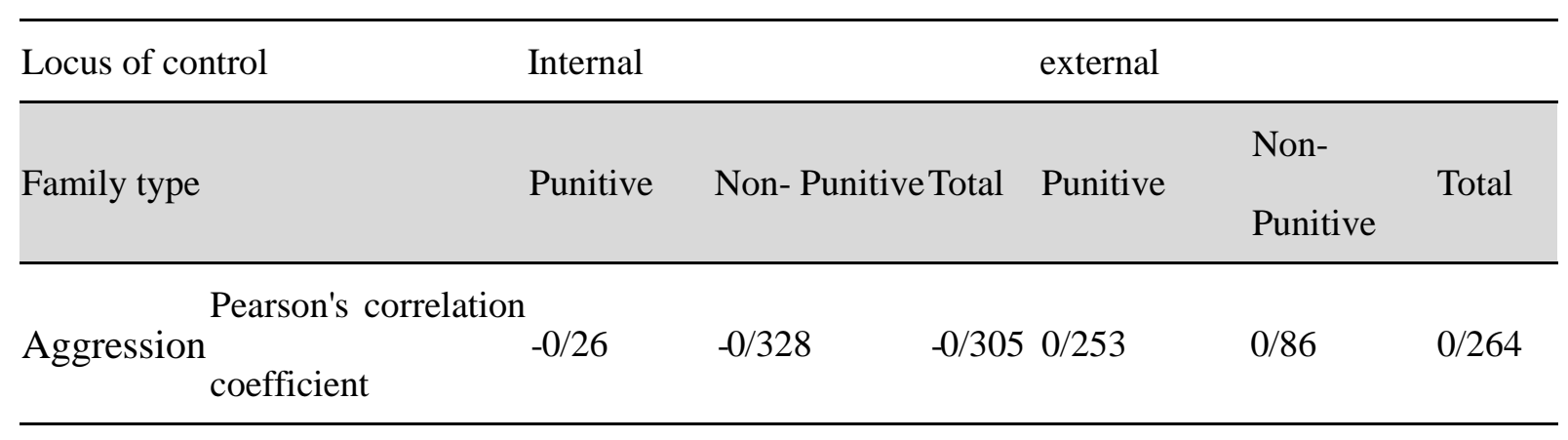




\begin{tabular}{lllllll}
\hline Significant level & $0 / 001$ & $0 / 535$ & $0 / 001$ & $0 / 001$ & $0 / 016$ & $0 / 001$ \\
\cline { 2 - 3 } & 286 & 54 & 340 & 286 & 54 & 340 \\
\hline
\end{tabular}

The above table indicates that the relationship between aggression and locus of control locus in separation of control (internal and external) and family (punitive and non-punitive). The test except in a case where the relationship of aggression with internal locus of control and non-punitive family (significant levels $\alpha=0.535$ is bigger than the specified value $p=0.535$ ) is accepted in other items.

First Hypothesis: There is a relationship between internal locus of control of parents and children's aggression in punitive families

Pearson correlation coefficient is used to analyze the results of the hypotheses, as it is shown in Table 4-10, the correlation coefficient for variable of internal locus of control and aggression $r=20 . .260$ and $\alpha=286$, which this value is meaningful in $p<001$ level and $\mathrm{n}=286$. Thus it can be concluded that there is a relationship between internal locus of control of parents and children's aggression in punitive families. The negative relationship indicates that parents with more tendencies to internal locus of control have children with less aggression.

Second Hypothesis: There is a relationship between external locus of control of parents and children's aggression in punitive families

Pearson correlation coefficient is used to analyze the results of the hypotheses, as it is shown in Table 4-10, the correlation coefficient for variable of internal locus of control and aggression $r=0.253$ and $\alpha=0.01$, which this value is meaningful in $p<001$ level and $n=286$. Thus it can be concluded that there is a relationship between external locus of control of parents and children's aggression in punitive families. The positive relationship indicates that parents with more tendencies to external locus of control have children with high aggression.

Third Hypothesis: There is a relationship between internal locus of control of parents and children's aggression in non-punitive families

Pearson correlation coefficient is used to analyze the results of the hypotheses, as it is shown in Table 4-10, the correlation coefficient for variable of internal locus of control and aggression $r=-0.328$ and $\alpha=0.016$, which this value is meaningful in $p<001$ level and 
$\mathrm{n}=54$. Thus it can be concluded that there is a relationship between internal locus of control of parents and children's aggression in non-punitive families. The negative relationship indicates that parents with more tendencies to internal locus of control have children with less aggression.

Fourth Hypothesis; There is a relationship between external locus of control of parents and children's aggression in non-punitive families

Pearson correlation coefficient is used to analyze the results of the hypotheses, as it is shown in Table 4-10, the correlation coefficient for variable of internal locus of control and aggression $r=0.086$ and $\alpha=0.016$, which this value is meaningful in $p<001$ level and $n=54$. Thus it can be concluded that there is a relationship between external locus of control of parents and children's aggression in non-punitive families.

Fifth Hypothesis; There is a relationship between internal locus of control of parents and children's aggression in non-punitive and punitive families

Pearson correlation coefficient is used to analyze the results of the hypotheses, as it is shown in Table 4-10, the correlation coefficient for variable of internal locus of control and aggression $r=-0.305$ and $\alpha=0.001$, which this value is meaningful in $p<001$ level and $\mathrm{n}=340$. Thus it can be concluded that there is a relationship between internal locus of control of parents and children's aggression in non-punitive and punitive families. The negative relationship indicates that parents with more tendencies to internal locus of control have children with less aggression.

Sixth Hypothesis: There is a relationship between external locus of control of parents and children's aggression in non-punitive and punitive families

Pearson correlation coefficient is used to analyze the results of the hypotheses, as it is shown in Table 4-10, the correlation coefficient for variable of internal locus of control and aggression $r=0.264$ and $\alpha=0.01$, which this value is meaningful in $p<005$ level and $n=340$. Thus it can be concluded that there is a relationship between external locus of control of parents and children's aggression in non-punitive and punitive families. The positive relationship indicates that parents with more tendencies to external locus of control have children with high aggression. 
Seventh Hypothesis: There is a difference in aggression between non-punitive and punitive families.

Table 2. t-test on independent variable related to aggression between non-punitive and punitive families

\begin{tabular}{llrrrrrr}
\hline Variable & Group & Frequency & Mean & $\begin{array}{r}\text { Standard } \\
\text { deviation }\end{array}$ & t & \multicolumn{2}{c}{$\begin{array}{l}\text { Sig } \\
\text { level }\end{array}$} \\
\hline \multirow{2}{*}{ Aggression } & non-punitive & 54 & $72 / 28$ & $9 / 916$ & & & \\
\cline { 2 - 5 } & Punitive & 286 & $88 / 67$ & $15 / 138$ & & $-7 / 647$ & $0 / 001$ \\
\hline
\end{tabular}

Homogeneity test of variables is used to analyze the results of the hypotheses, as it is shown in Table 4-11, the significant level of 0.001 is less than acceptable value, $\alpha=0.05$, thus it is concluded that there is a significant difference in aggression between non-punitive and punitive families. The mean of aggression point in two groups is 72.28 for non-punitive and 88.67 for punitive that indicates there is a significant difference.

Eighth Hypothesis: There is a difference between external locus of control of non-punitive and punitive families.

Table 3. $t$-test on independent variable related to external locus of control of non-punitive and punitive families

\begin{tabular}{|c|c|c|c|c|c|c|c|c|}
\hline Variable & Group & Frequency & Mean & $\begin{array}{l}\text { Standard } \\
\text { deviation }\end{array}$ & df & & & Sig level \\
\hline External & non-punitive & 54 & $15 / 20$ & $2 / 382$ & & & $2 / 620$ & 0/009 \\
\hline $\begin{array}{l}\text { locus of } \\
\text { control }\end{array}$ & Punitive & 286 & $14 / 35$ & $2 / 150$ & & 338 & & \\
\hline
\end{tabular}

Homogeneity test of variables is used to analyze the results of the hypotheses, as it is shown in Table 4-12, the significant level of 0.009 is less than acceptable value, $\alpha=0.05$, thus it is concluded that there is a significant difference between external locus of control of 
non-punitive and punitive families. The mean of external locus of control point in two groups is 15.20 for non-punitive and 14.35 for punitive that indicates there is a significant difference Ninth Hypothesis: There is a difference between internal locus of control of non-punitive and punitive families.

Table 4. t-test on independent variable related to internal locus of control of non-punitive and punitive families

\begin{tabular}{|c|c|c|c|c|c|c|c|}
\hline Variable & Group & Frequency & Mean & $\begin{array}{l}\text { Standard } \\
\text { deviation }\end{array}$ & $\mathrm{df}$ & $\mathrm{t}$ & Sig level \\
\hline Internal & non-punitive & 54 & $13 / 69$ & $2 / 239$ & & & \\
\hline $\begin{array}{l}\text { locus of } \\
\text { control }\end{array}$ & Punitive & 286 & $14 / 67$ & $2 / 124$ & 338 & $-3 / 092$ & $0 / 002$ \\
\hline
\end{tabular}

Homogeneity test of variables is used to analyze the results of the hypotheses, as it is shown in Table 4-13, the significant level of 0.002 is less than acceptable value, $\alpha=0.05$, thus it is concluded that there is a significant difference between internal locus of control of non-punitive and punitive families. The mean of external locus of control point in two groups is 13.69 for non-punitive and 14.67 for punitive that indicates there is a significant difference.

\section{CONCLUSION}

Among the methods of behavior modification, great coaches and psychologists have always been suspicious of the use of corporal punishment and have warned against using it. Using this method is not acceptable due to many reasons; it is not clear that with using punishment we reach the desirable results in one hand and in another hand, it takes great effort to do that so at the end the punisher will get tired or surrender, so there is a possibility that behavior changes or even strengthened.

According to the findings, it was found that parents with more tendencies towards internal locus of control in punitive families will have children with low aggression; parents with more tendencies towards external locus of control in punitive families will have children with high aggression; parents with more tendencies towards internal locus of control in 
non-punitive families will have children with low aggression, the external locus of control in non-punitive families affect children's aggression; parents with more tendencies towards internal locus of control will have children with low aggression; parents with more tendencies towards external locus of control will have children with high aggression; there is a significant difference between aggression and punitive and non-punitive families; there is a significant difference between external locus of control between punitive and non-punitive families; there is a significant difference between internal locus of control between punitive and non-punitive families.

\section{REFERENCES}

[1] Ayin, Farhad (2005) Social risk families, vulnerable children: What is an effective strategy? Journal of Pediatrics Children's Special Seventeenth International Conference Sciences, Medical and Health Services, Tehran, 2005, Volume 15, Supplement 1: 218.

[2] Khoynejad, Gholamreza, RejayiAlireza, ShakibAbdolhamid, RahimiFatemeh (2008). A comparison of job stress-external locus of control on school administrators, Journal of Educational Branch Number Bojnoord XVI, fall.

[3] Shams Ashkan (2010). How behave with our aggressive child behavior, mental health and community magazine, the fifth year, half of April - No. 18 (from page 18 to 20).

[4] GhasemeiFatemeh, ValizadehFatemeh, ToulabiTahereh, Saki Mandana (2007). Check out some behavioral problems caused by corporal punishment by parents of school children, Journal of the findings, Lorestan University of Medical Sciences, Volume IX, and Issue 4.

[5] Mohammadi, Ebrahim (2011): The consequences of corporal punishment, Journal of Education, May - No. 88.

[6] Malekpour, Mokhtar (2010): The relationship between punishment and self-expression in children and adolescents, Journal of Education (Education), Summer - No. 50. 
[7] Gofin R, LevaI, Kohn R (2009), Attitudes and opinions on corporal punishment among urban Israeil Jews. Isr J Psychiatry Relat Sci; 41 (2): 90.

[8] Lopez SC, Lara MG, Amighetti LD et al. Parenting and physical primary punishment: care interventions in Latin America. Rev PanamSaludPublica. 2000; 8 (4): 257-67.

[9] Wolrich M, Aceves J, Feldman HM, Hagan JF, Howard BJ,Richtsmeier AJ, et al. Guidance for effective discipline. PEDIATRICS. 1998, 101 (4): 723-728.

\section{How to cite this article:}

Shojaei $\mathrm{H}$ and Zarei E. The relationship between internal and external locus of control of parents with aggression in children in punitive and non-punitive families in Mashhad. J. Fundam. Appl. Sci., 2016, 8(4S), 2084-2094. 